\title{
A VISITAÇÃO TÉCNICA ORIENTADA: UMA PROPOSTA DE INTEGRAÇÃO ESCOLA- INDÚSTRIA PARA A FORMAÇÃO DOS TÉCNICOS EM QUÍMICA
}

\author{
Rafael Lopes da Costa \\ Guilherme Cordeiro da Graça de Oliveira \\ Paula Macedo Lessa dos Santos
}

\section{Introdução}

Este capítulo se propõe a apresentar o resultado de uma pesquisa de dissertação que resultou na elaboração de um guia prático feito com foco no professor do ensino médio técnico em Química ou àqueles docentes que já realizam visitas técnicas às indústrias Químicas ou áreas afins com os estudantes. Um material elaborado para contribuir com o trabalho do docente que tem o interesse em incorporar visitações técnicas no seu planejamento pedagógico.

A escola técnica em Química do século XXI deve proporcionar aos alunos um espaço vivo, onde sejam considerados os vários aspectos das relações humanas, sejam eles sociais, políticos, culturais, econômicos ou quaisquer outros. As salas de aula e os laboratórios escolares trazem 
as teorias acadêmicas; em oposição a estes, os espaços não convencionais, fora da escola, tais como indústrias, museus e centros de ciências, ampliam o acesso à cultura e ao conhecimento prático-profissional.

Célestin Freinet, na década de 1920, foi um dos primeiros professores a sair com seus alunos do espaço escolar para promover em outros lugares o estudo de elementos neles disponíveis (SAMPAIO, 2002). O educador francês relata em sua obra as visitas técnicas que usou para observar assuntos relevantes em sua disciplina - ele diz que no reinício das aulas à tarde, toda a turma saía para o campo que circundava a aldeia. No decorrer da caminhada pelas ruas, paravam para admirar trabalhadores como o ferreiro, o marceneiro ou o tecelão, cujos movimentos metódicos e seguros despertavam a vontade de imitá-los. Freinet descreve todas as paisagens do caminho e em diferentes épocas do ano, detalhando inclusive os insetos e flores que observavam (FREINET, 1998).

A prática da visita industrial guiada vislumbra a necessidade da caracterização dos espaços não formais de aprendizagem na construção do conhecimento e do desenvolvimento do aluno, inclusive de Química. Portanto, a importância da visita técnica industrial como recurso metodológico de ensino deve ser considerada na educação profissional. Todos os discentes precisam ter a oportunidade de conhecer e verificar as aulas práticas e o funcionamento nas empresas e no mercado de trabalho, co- 
mo forma de rever os conceitos teórico-metodológicos e expressar o diálogo produzido em sala de aula (SANTOS, 2006).

Nos dias atuais, para que tenhamos um bom desenvolvimento nas práticas educativas dos estudantes, esses precisam ser motivados, precisam estar em constante aprendizagem. Como afirma Japiassu (2006, p. 54):

O sistema educativo deve promover uma formação que não seja um fechamento disciplinar e um adestramento ao pensamento apenas aplicando receitas disciplinares, mas criando projetos ricos de diversidade humana e tecendo pontos de vista e ordens de pensamento diferentes. Aquilo que mais precisamos hoje não é tanto de instrumentos, mas de cultura, permitindo-nos incentivar os estudantes, não só a ampliar o campo de seus conhecimentos, mas a descobri-los, compreendê-los, aprofundá-los sempre mais.

Pesquisas bibliográficas, como em Costa (2019), mostram que a falta de motivação no processo ensino/aprendizagem pode contribuir muito para o desinteresse, a evasão escolar e para a formação de um indivíduo sem atitude, passivo de opinião. Ainda mais quando falamos de uma formação técnica em Química, em que o aluno fica preso a várias fórmulas, símbolos e cálculos, tudo muito teórico e abstrato. Sendo assim, a educação através da visita técnica, quando elaborada para os devi- 
dos fins, permite ao educando a aprendizagem de conceitos e atitudes corretas por meio da participação, observação ou reprodução do cotidiano, e a integração com o conhecimento escolar (ARTIGAS, 2002).

Importante salientar que as visitações técnicas não devem ser tratadas como um simples passeio, sem um ritual de formalidades didáticas e pedagógicas. Sendo assim, devem ser preparadas para que os alunos tenham o aprendizado focado em várias disciplinas, tornando-a um catalisador para a aprendizagem (VELOSO, 2000). Desta forma, a visita técnica deve proporcionar uma captura de informações do mundo concreto que possibilite o "desenvolvimento do pensamento analítico, ou seja, da decomposição do mundo concreto em partes e da criação de novas sínteses" (SILVA; MACHADO; TUNES, 2010, p.239). Devem também possibilitar a interação, mesmo que só visual, do aluno com a realidade da indústria. Mostrar ao aluno a importância dos conteúdos ministrados na escola, em sala de aula e nos laboratórios, além de exercer um papel fundamental para a formação dos futuros profissionais técnicos Químicos. Costa (2019), defende que é de suma importância a realização das visitas técnicas no decorrer do curso técnico em Química, por ser uma atividade que motiva o aluno e possibilita o contato com as mais modernas tecnologias, suas inovações e aplicações. 
Em sua pesquisa, Costa (2019), aponta que a maioria dos alunos do ensino técnico em Química do Centro Vocacional Tecnológico - FAETEC CVT Nova Iguaçu, sempre tiveram o interesse em saber como funciona a rotina de um profissional técnico químico em uma indústria, as suas responsabilidades dentro de um laboratório, quais as análises Químicas são realizadas nos laboratórios industriais e como funciona a linha de produção de uma indústria da área. O autor ainda relata que, apesar de realizar visitas técnicas orientadas, constantemente surgiam dúvidas a respeito de como elaborar uma aula externa que envolvesse uma indústria, seus produtos e processos. Refletia-se sobre quais os temas, os recursos e as ferramentas a serem utilizados antes, durante e depois da realização da visitação, pois há uma grande dificuldade em encontrar materiais de apoio que dessem suporte ao professor para explorar o potencial formativo das visitas técnicas e a sua elaboração. Toda visita técnica deve ter um propósito bem claro: o professor é o responsável pelo seu planejamento e por desenvolver as ações que otimizem os resultados da experiência prática (GOMES et al, 2014).

Este capítulo contém um material auxiliador na elaboração de uma sequência didática (SD) que envolve o planejamento e a execução de uma visitação técnica orientada (VTO) a uma indústria Química cosmética e nas atividades a serem elaboradas na pós-visitação com o grupo de alunos que participaram da atividade. $\mathrm{O}$ mesmo 
é o produto da dissertação intitulada "SEQUÊNCIA DIDÁTICA APLICADA AO ENSINO TÉCNICO EM QUÍMICA: da visitação à indústria ao laboratório escolar”, defendida no ano de 2019.

\section{Sequência Didática (SD): o que é?}

Trata-se de um processo de ensino e aprendizagem motivador com atividades interligadas, planejadas pelo docente de acordo com o seu público-alvo, com o objetivo de ensinar um conteúdo. As sequências didáticas possibilitam unir e trabalhar diferentes atividades ao longo da sua execução a fim de despertar no aluno o desejo de participar ativamente da construção do conhecimento desses diferentes conteúdos (ZABALA, 1998).

A elaboração e execução de uma boa SD possibilita a troca de conhecimentos entre o educando e o educador. Durante a atividade, com o passar do tempo, o aluno vai sendo mediado e orientado pelo professor até a construção do conhecimento desejado. Em contrapartida, o professor deixa de ser um reprodutor de informações e, em conjunto, colabora para a autoaprendizagem dos seus alunos (COSTA, 2019).

Partindo-se das contribuições de Zabala e com a finalidade de desenvolver uma SD que possibilite estabelecer correlações entre o "mundo" industrial e a vida aca- 
dêmica dos estudantes do curso técnico em Química, foi elaborado o produto "GUIA PRÁTICO PARA VISITAÇÃO TÉCNICA ORIENTADA: da visitação à indústria ao laboratório escolar"1.

A seguir, será apresentada a metodologia da pesquisa e a construção da SD desenvolvida. Essa se divide em três partes: abordagem metodológica, apresentação da indústria e descrição da pesquisa, incluindo os procedimentos antes, durante e depois da visitação.

\section{Percurso metodológico e o desenvolvimento do pro- duto}

O guia prático foi concebido de forma a apresentar uma SD com diretrizes que visam ajudar o professor a elaborar, no seu planejamento anual disciplinar, atividades pedagógicas que proporcionem uma aproximação entre aluno e o ambiente industrial.

É importante ter em mente que, para que se alcance os objetivos pedagógicos, a visitação técnica orientada deve ser bem planejada, não podendo ser tratada

1 Esse guia pode ser acessado pelo link: https://drive.google.com/file/d/1FQjNLtwGUJWBeFT3HJrSrniFsY Y15Lb6/view. 
meramente como uma "aula passeio" (COSTA, 2019). Essa deve ter objetivos bem definidos e claros, devendo o professor se questionar por que e para que essa atividade deve ser elaborada. Segundo Giordan e colaboradores (2011) a sequência didática vem adquirindo relevância na área de Educação desde a década de 1970. O docente ao planejar e elaborar uma sequência didática deve levar em consideração as contribuições do processo de ensino e aprendizagem, com atividades inter-relacionadas com a prática profissional e que visem, portanto, tornar o processo formativo mais significativo.

\section{Tipo de pesquisa}

A metodologia empregada nesse trabalho caracteriza-se como uma pesquisa-ação, uma vez que proporciona e realiza uma estreita relação entre uma situação problema e a ação que intervém. Na literatura a pesquisaação é definida por (THIOLLENT, 1986), como:

[...] um tipo de pesquisa social com base empírica que é concebida e realizada em estreita resolução de um problema coletivo e no qual os pesquisadores e os participantes representativos da situação ou do problema estão envolvidos de modo cooperativo ou participativo (THIOLLENT, 1986, p. 14). 
Esse tipo de pesquisa pode ser aplicado em diversas áreas e em educação, pois possibilita a descrição, avaliação e a participação de todos os envolvidos na atividade, na busca de solução para os problemas que possam existir.

\section{Características da instituição de ensino e do público- alvo}

O público-alvo deste trabalho foram 23 alunos da turma da $2^{\text {a }}$ etapa do ano de 2018 do curso técnico em Química (com ênfase em cosméticos) da Rede Pública Estadual - FAETEC CVT, localizada no município de Nova Iguaçu - RJ.

A carga horária composta por disciplinas de Físico - Química teórica (quatro tempos de 50 minutos semanais), Química analítica qualitativa teórica (quatro tempos de 50 minutos semanais) e Química analítica qualitativa experimental (dois tempos de 50 minutos semanais) no segundo módulo do curso, sempre levavam os alunos a questionarem o professor das disciplinas sobre os conteúdos e métodos teóricos e experimentais utilizados durante as aulas, através de perguntas do tipo: "isso vai ser utilizado na indústria como?”; “os equipamentos que temos aqui no nosso laboratório são iguais ao da indústria?"; "pra que temos que aprender isso?"; "como é a rotina de um laboratório químico industrial?”; “qual é a 
função de um técnico em Química dentro de uma indústria cosmética?”.

Com o intuito de responder a esses questionamentos foi proposta uma aula externa em um ambiente industrial, uma VTO, para que assim os alunos pudessem ver sentido nos conteúdos estudados e experimentos realizados durante as aulas na escola.

A metodologia envolvida neste trabalho foi elaborada pensando na realidade do público-alvo da pesquisa e permitiu a criação e a execução de uma série de atividades integradas que possibilitaram mostrar os conteúdos a serem trabalhados de maneira significativa para os alunos.

Parte da pesquisa foi desenvolvida por meio de uma visita técnica orientada (VTO) a uma indústria cosmética localizada na cidade de Japeri que, assim como Nova Iguaçu, faz parte dos municípios que compõem a Baixada Fluminense - RJ. A ideia era desenvolver uma atividade que colaborasse com o processo de ensinoaprendizagem realizado em sala de aula, proporcionar aos estudantes a oportunidade de observarem a rotina de uma indústria e de seus funcionários, além de promover um maior interesse e engajamento dos estudantes pelo curso técnico em Química. 
As etapas das atividades realizadas que contemplaram a preparação para a visita, a visita ao espaço da fábrica e os experimentos no laboratório escolar foram as seguintes:

$1^{\circ}$ - Conversa com o grupo de alunos para obter conhecimento prévio sobre a abordagem da atividade a ser realizada;

$2^{\circ}$ - Discussão com os alunos sobre a escolha da fábrica para a VTO e a forma de deslocamento do grupo para chegar à fábrica;

$3^{\circ}$ - Execução da VTO;

$4^{\circ}$ - Seleção de experimentos a serem realizados no laboratório da escola técnica: produção de cosméticos $e$ extração de óleos essenciais de plantas aromáticas.

A partir das respostas dos alunos durante a conversa, foi elaborada e estruturada a SD articulada com os conteúdos abordados em sala de aula.

Os dois primeiros passos da SD proposta foram realizar conversas e discussões com a turma para entender a necessidade do grupo. No terceiro ponto, foi realizada a VTO com o grupo. Por fim, os alunos foram para o laboratório escolar para realizar a extração de óleo essen- 
cial e produzir cosméticos, reproduzindo, em menor escala, parte do que foi visto na VTO.

\section{Instrumento de coleta dos dados}

Para avaliar a impressão dos alunos em relação à VTO foi utilizado um questionário em escala de Likert o qual constitui um processo de escalonamento proposto por Rensis Likert e é um tipo de instrumento de respostas psicométricas composto por um conjunto de itens ou assertivas (OLIVEIRA; SILVA, 2016).

\section{A indústria escolhida para a visitação}

Localizada no município de Japeri - RJ, a indústria cosmética escolhida para a visitação é uma empresa moderna que investe em treinamento para seus funcionários e em novos equipamentos, isso possibilitou um aumento da sua eficiência e uma melhor qualidade dos seus produtos (Figura 1). 
Figura 1. Fachada principal da entrada lateral da fábrica de cosméticos localizada no município de Japeri.

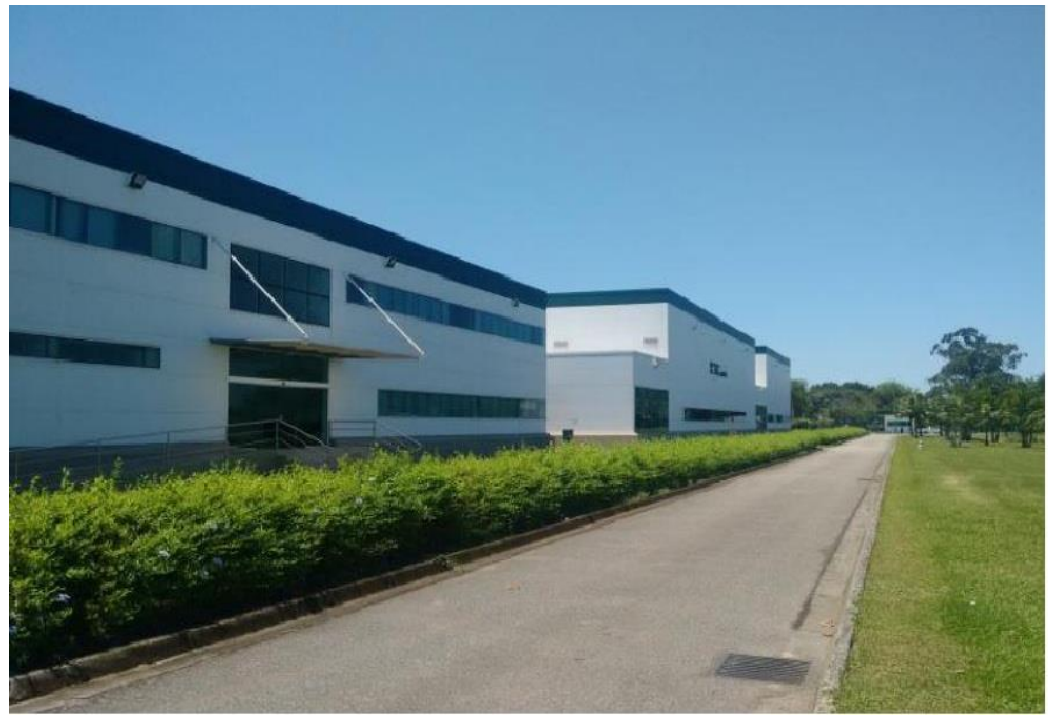

Fonte: autor

\section{Planejamento das atividades}

O planejamento das atividades para o estabelecimento de uma SD foi concebido a partir do pressuposto de que a VTO seria uma visita com fins educativos a um Espaço Não Formal (ENF) de ensino.

Metodologicamente optou-se pelas visitas dos tipos: LIMITADA DO TIPO 2 - tipo de visita que não restringe o espaço, os estudantes escolhem e controlam o roteiro de acordo com uma programação previamente 
discutida com o professor ou apresentada pelo espaço visitado (SANTOS, 2017) e SEM ESCOLHA - caracteriza-se pelo caráter expositivo. O roteiro é limitado por um guia e normalmente os estudantes são orientados a seguir a exposição, sem qualquer responsabilidade ou controle sobre os assuntos apresentados (SANTOS, 2017).

Segundo Oliveira, et al. (2014) a visita limitada possibilita ao aluno durante a visitação, expressar um grande envolvimento com os assuntos que estão sendo tratados. Já Bamberger e Tal (2006) afirmam que a visita sem escolha configura-se pelo caráter expositivo. $\mathrm{O}$ roteiro é limitado por um guia e normalmente os estudantes são orientados a assistir à exposição, sem qualquer responsabilidade ou controle sobre os assuntos apresentados.

No Quadro 1 é apresentado o planejamento das atividades considerando-se as etapas de pré-visita, visita e pós-visita utilizados neste trabalho. 
Quadro 1. Planejamento das atividades desde o contato prévio com a empresa até a discussão dos resultados das análises.

\begin{tabular}{|c|c|}
\hline Etapa & Ativida des \\
\hline \multirow{4}{*}{ Pré-visita } & Conversa com a turma/grupo que vai realizar a visitação. \\
\hline & Pesquisas sobre as possiveis opções de indústrias a serem visitadas. \\
\hline & Comunicação com a indústria. \\
\hline & Elaboração dos roteiros de observações para a visita. \\
\hline \multirow{3}{*}{ Visita } & O local de encontro: reunião com os alunos antes da entrada na fábrica. \\
\hline & A recepção do guia: momento que o guia explica como se dará a visitação. \\
\hline & Início e fim do tour pela fábrica. \\
\hline \multirow{4}{*}{ Pós-visita } & Avaliação da vista pelos estudantes do ensino técnico em química. \\
\hline & $\begin{array}{l}\text { Aula no laboratório da escola técnica: formulação de cosméticos e extração } \\
\text { de óleos essenciais de matéria-prima vegetal. }\end{array}$ \\
\hline & Isolamento e análise dos óleos essenciais nos laboratórios da universidade. \\
\hline & $\begin{array}{l}\text { Discussão dos resultados da análise por CG-EM com os estudantes do curso } \\
\text { técnico em química. }\end{array}$ \\
\hline
\end{tabular}

Fonte: elaborado pelo autor.

\section{A visitação}

Os 23 alunos envolvidos na atividade, todos maiores de idade, optaram por utilizar o transporte coletivo para chegarem à fábrica. $\mathrm{O}$ ponto de encontro para que $\mathrm{o}$ grupo se reunisse antes da realização da visita foi em frente ao portão principal de entrada da fábrica às o8h3omin do dia 10/04/2018, já que o horário agendado 
pela empresa foi às 9 horas. Ao chegar à portaria da fábrica, às 08h40min, o professor se deparou com somente 17 alunos, os outros 6 alunos não compareceram por motivos pessoais diversos.

Às 09ho5min, horário que foi dada a autorização da portaria da empresa para que o grupo entrasse no parque industrial, individualmente, todos receberam, ainda na portaria, um crachá de identificação de visitantes. $\mathrm{O}$ grupo foi orientado a seguir até a recepção interna e aguardou a chegada do responsável (guia) da empresa. Somente após a chegada do guia, que se apresentou e passou todas as orientações sobre os procedimentos, é que a visitação realmente teve início.

\section{A pós-visitação}

Terminada a visitação, ainda na fábrica, todos os visitantes foram direcionados para a portaria principal, onde foram recolhidos os crachás e cada visitante seguiu seu destino individualmente.

Na aula seguinte, já na escola, foi aplicado o questionário em escala de Likert de cinco níveis, para conhecer as impressões dos alunos em relação à atividade realizada. O questionário (Figura 2) avaliou duas dimensões: aspectos afetivos e aspectos cognitivos. Esse proce- 
dimento já foi adotado na literatura por Oliveira et al., (2014) e Oliveira, et al., (2016).

Figura 2. Questionário com as assertivas destinadas aos alunos participantes da VTO

\title{
VISITA TECNICA REALIZADA NA FABRICA DA GRANADO.
}

Questionảrio aos Alunos

\begin{abstract}
Por favor, assinale com um $(\mathbf{X})$ a opçăo com a qual concorda. Não há resposta certa ou errada, o importante é sua opiniấo sincera.

1 - Discordo totalmente; 2 - Discordo parcialmente; 3 - Não concordo, nem discordo; 4 - Concordo parcialmente; 5 - Concordo totalmente.
\end{abstract}

\begin{tabular}{|c|c|c|c|c|c|c|}
\hline & Assertivas & 1 & 2 & 3 & 4 & 5 \\
\hline 1 & Eu gostei da visitaç̧̄o que foi realizads. & & & & & \\
\hline 2 & Eu acho importante realizar ma is atividades como esta. & & & & & \\
\hline 3 & Aprendi coisas importantes de química durante a atividade. & & & & & \\
\hline 4 & Aprendi coisas importantes de uma maneira peral. & & & & & \\
\hline 5 & $\begin{array}{l}\text { As observaçöes realizadas nesta atividade foram } \\
\text { importantes para minha formaçäo como técnico em } \\
\text { Cuimics. }\end{array}$ & & & & & \\
\hline 6 & $\begin{array}{l}\text { Gostei das observaçbes e questionamentos realizados } \\
\text { durante a visitacăo. }\end{array}$ & & & & & \\
\hline 7 & $\begin{array}{l}\text { Durante a visitação pude compreender a importânoia da } \\
\text { organczaço e higiene no local de trabaiho. }\end{array}$ & & & & & \\
\hline 8 & $\begin{array}{l}\text { A visitaçăo me ajudou a compreender o processo de } \\
\text { fabricaça industrial de cosmétioos. }\end{array}$ & & & & & \\
\hline 9 & $\begin{array}{l}\text { A. visitação fez com que eu entendesse s importância de um } \\
\text { técnico em quimica para uma indústris. }\end{array}$ & & & & & \\
\hline 10 & $\begin{array}{l}\text { A visitaçăo me fez entender o motivo das cobranças em } \\
\text { releçäo ao meu oomportamento (cooperaçäo, concentraçäo, } \\
\text { biossegurança) durante as sulas experiments is de laboratónio } \\
\text { na escola. }\end{array}$ & & & & & \\
\hline 11 & $\begin{array}{l}\text { Realizar essa visitaçäo aumentou minhs vontade de } \\
\text { trabalhar ng śres de Quimics. }\end{array}$ & & & & & \\
\hline 12 & $\begin{array}{l}\text { Conheci novos equipamentos e instrumentos de laboratónio } \\
\text { quimico durante a visitaçâo. }\end{array}$ & & & & & \\
\hline 13 & $\begin{array}{l}\text { Dursnte a vistaçäo percebi a importâncla do trabalho em } \\
\text { equipe. }\end{array}$ & & & & & \\
\hline 14 & Durante a visitaçăo percebi a importância do uso do EP1. & & & & & \\
\hline 15 & $\begin{array}{l}\text { Durante a visitaçăo verifiquei a presença do EPC nos } \\
\text { ambientes da fábrico. }\end{array}$ & & & & & \\
\hline
\end{tabular}

Fonte: elaborado pelo autor

O questionário era composto por 15 assertivas onde foi possível ao aluno manifestar sua concordância numa escala entre "discordo totalmente" e "concordo 
totalmente". As assertivas 3, 4, 7, 8, 9, 10, 12, 13, 14 e 15 analisam os ganhos cognitivos (ex: "Aprendi coisas importantes de química durante a atividade" e "Durante a visitação verifiquei a presença do EPC nos ambientes da fábrica") e as assertivas 1, 2, 5, 6 e 11, que avaliam, na visão do aluno, os ganhos afetivos, o envolvimento pessoal com a atividade (ex: "Eu gostei da visitação que foi realizada" e "Realizar essa visitação aumentou minha vontade de trabalhar na área de química").

\section{Aula no laboratório escolar}

\section{Produção de cosméticos}

Para cumprir a forma de avaliação tradicional da instituição, foi proposta a realização de aula prática com produção de cosméticos, já que esta é a ênfase do curso. Satisfeitos, os alunos sugeriram a produção de alguns cosméticos similares aos vistos durante a aula externa na indústria.

O professor solicitou à direção do CVT que comprasse os reagentes e materiais necessários para a aula prática. Na semana seguinte, já com todos os reagentes disponíveis, foi agendada a aula experimental no laboratório da escola com a turma. Os grupos foram formados com máximo de 4 alunos e seguindo o roteiro prático 
elaborado pelo professor. Cada grupo escolheu o cosmético a ser reproduzido. Foram produzidos: xampus, sabonetes líquidos, loções pós-banho bifásicas, cremes hidratantes para as mãos e gel para massagem com cânfora e mentol (Figura 3).

Figura 3. Aula experimental: alunos produzindo cosméticos no laboratório escolar.

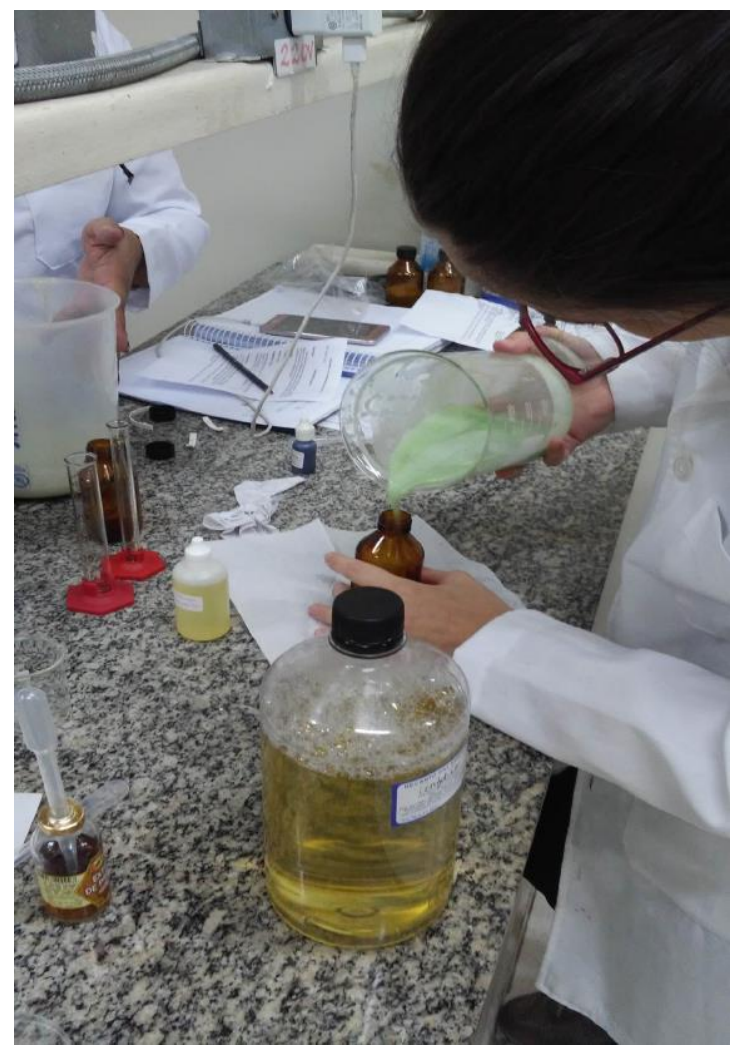

Fonte: autor 


\section{Extração de óleos essenciais}

Para a extração dos óleos essenciais foram utilizados os métodos de hidrodestilação e destilação por arraste e vapor, que possibilitam a separação das substâncias ativas existentes na matéria prima vegetal por diferença de volatilidade dos compostos.

Para esse trabalho foram utilizadas duas espécies vegetais: o cravo-da-índia, adquirido no comércio, e o capim-limão, levado pelos alunos. O cravo-da-índia comercial é o botão floral seco da espécie vegetal Syzygium aromaticum (L.) pertencente à família Myrtaceae, originária da Índia e cultivada em vários países tropicais, inclusive no Brasil (Lorenzi \& Matos, 2008). Já o material vegetal apresentado como capim-limão não era de origem comercial e não foi submetido à identificação botânica. Portanto, não se pode afirmar que se trata da espécie Cymbopogon citratus (DC) Starf, pertencente à família Poaceae, que recebe os nomes populares de capimlimão, erva-cidreira, capim-cidreira, dentre outros (Lorenzi \& Matos, 2008).

Para a extração dos óleos essenciais foram utilizadas duas técnicas de extração: a extração por arraste de vapor e a hidrodestilação, baseadas em técnicas de laboratório de química orgânica (Pavia et al., 2009). Ambas as técnicas utilizam a aparelhagem de destilação, em que o vapor d'água carreia os vapores dos óleos voláteis pre- 
sentes no material vegetal. Na fase vapor, a água e os vapores dos compostos voláteis são miscíveis e, ao passarem pelo condensador, tornam-se líquidos. Na saída do condensador, os líquidos são recolhidos. A indústria prefere a destilação com arraste a vapor devido à sua maior simplicidade e economia, pois permite tratar de uma única vez quantidades significativas de material vegetal (Guenther, 1976).

Para proceder à destilação por arraste de vapor pelo método indireto (Figura 4), com o auxílio de uma manta de aquecimento, $350 \mathrm{~mL}$ de água destilada foram aquecidos em um balão de fundo redondo de $1000 \mathrm{~mL}$. Esse balão foi ligado, com o auxílio de uma haste de vidro, com formato curvo, ao balão de três saídas que continha $250 \mathrm{~g}$ do material vegetal picado em pequenos pedaços. Ao balão de três saídas também estavam conectados: um termômetro e o destilador de serpentina. Durante a ebulição da água, os vapores produzidos foram direcionados para o material vegetal (balão de três saídas). Os vapores de água e óleos essenciais formados no balão de três saídas foram conduzidos para o condensador de serpentina e recolhidos em Erlenmeyer. O sistema de resfriamento do condensador utilizou uma bomba pequena de aquário, mangueiras de água, um balde pequeno, água da torneira e algumas pedras de gelo. Esse método foi elaborado e adaptado pelo pesquisador e seus orientadores pensando nos problemas de desperdício e falta de água potável no planeta e na cidade de Nova Igu- 
açu, um pequeno gesto que contribuiu para o não desperdício de água durante a realização da atividade. Parte dos equipamentos e vidrarias utilizados durante a realização das aulas práticas foi cedida pelos professores orientadores da pesquisa.

Figura 4. Sistema de destilação com vapor pelo método indireto para a obtenção do óleo essencial de capim-limão.

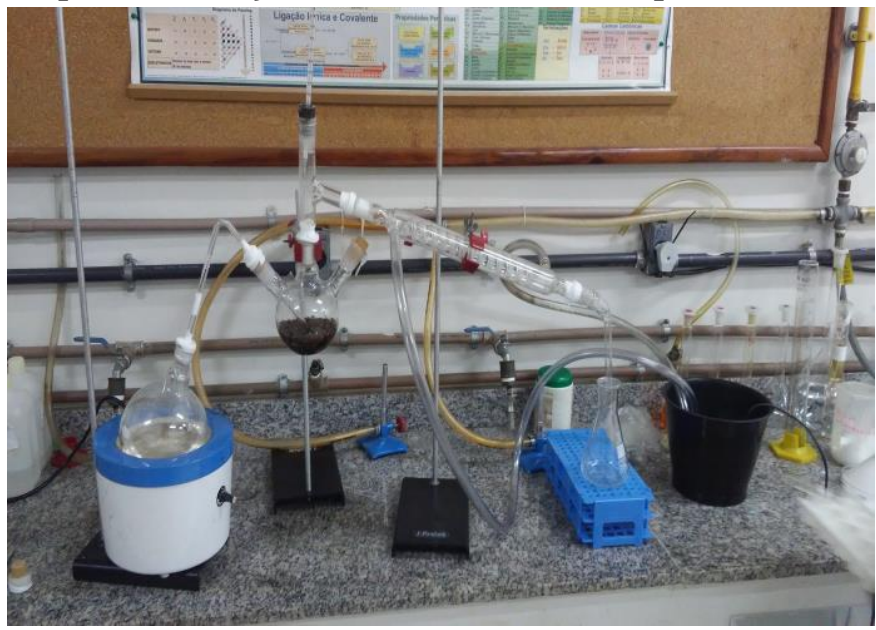

Fonte: autor

A destilação por arraste de vapor pelo método direto foi realizada com o auxílio de um só balão de fundo redondo de (1000 $\mathrm{mL})$ com somente uma saída. Foram adicionados ao balão (30 g) do material vegetal (cravoda-índia) e (200 $\mathrm{mL})$ de água destilada. Ao balão, também estavam conectados: um termômetro - para o controle da temperatura e o destilador de serpentina. Durante a ebulição da mistura, os vapores produzidos pela água 
e pelos compostos voláteis do material vegetal foram conduzidos para o condensador reto e recolhidos em Erlenmeyer (Figura 5). Para não haver desperdício de água, também foi utilizado no sistema de resfriamento do condensador uma bomba pequena de aquário, mangueiras de água, um bécher de plástico de (2000 $\mathrm{mL})$, água da torneira e algumas pedras de gelo.

Figura 5. Sistema de destilação com vapor pelo método direto para obtenção do óleo de cravo.

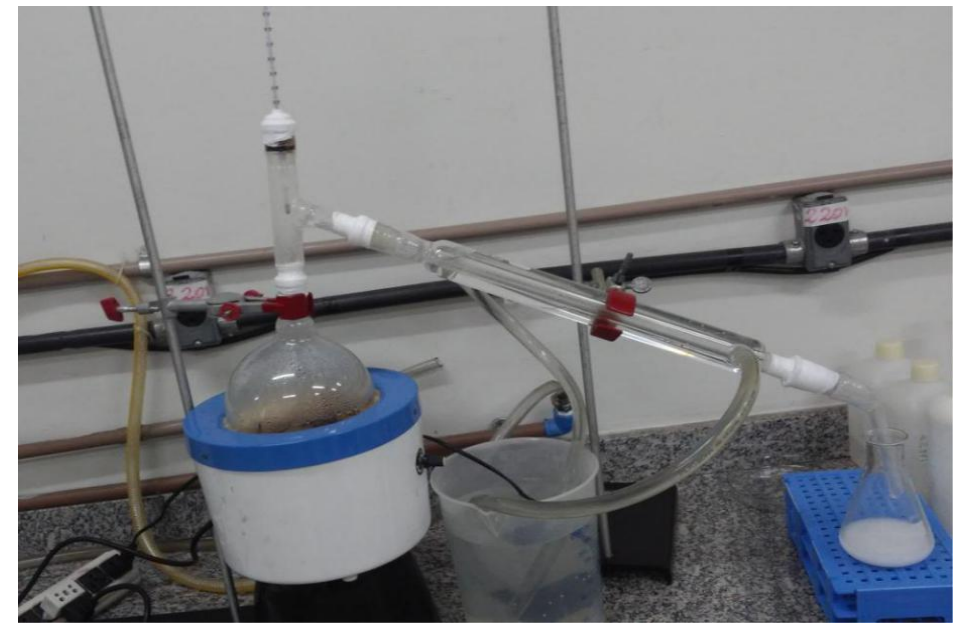

Fonte: autor

\section{Tratamento das amostras e análise das amostras}

Após a etapa de extração dos óleos essenciais de cravo-da-índia e de capim-limão, os hidrolatos foram 
transferidos para frascos de vidro tipo âmbar, logo após, os frascos foram fechados e mantidos sob refrigeração para posterior purificação. As amostras foram tratadas e analisadas nos laboratórios do Instituto de Química da UFRJ (Figura 6). Todos os solventes utilizados no tratamento das amostras foram em grau analítico.

Figura 6. Extração líquido/líquido do óleo essencial de capimlimão.

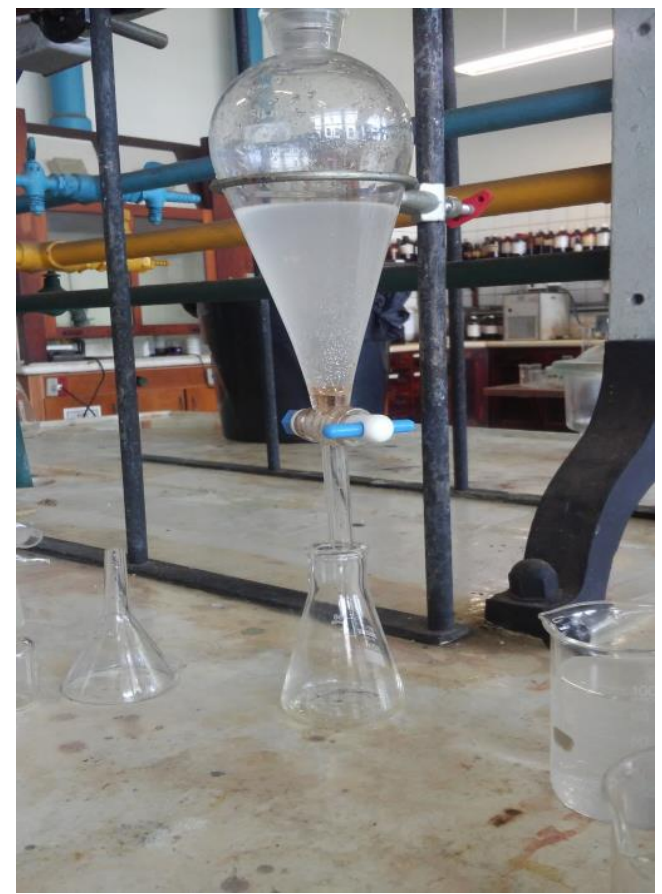

Fonte: autor

A amostra contendo óleo essencial de cravo-daíndia foi particionada com éter etílico $(3 \times 5 \mathrm{~mL})$ em funil 
de separação e a fase orgânica foi recolhida. Posteriormente, essa fase orgânica foi levada ao rotavapor (Figura 7) para a remoção do solvente.

Os dois óleos essenciais foram submetidos à análise por cromatografia em fase gasosa acoplada à espectrometria de massas (CG-EM). Os componentes majoritários detectados no óleo essencial de cravo-da-índia ( $S y$ zygium aromaticum) foram o eugenol e o acetato de eugenila, e no óleo essencial da amostra indicada como capim-limão, foram os isômeros do citral.

Figura 7. Concentração do óleo essencial de cravo da índia em rotavapor.

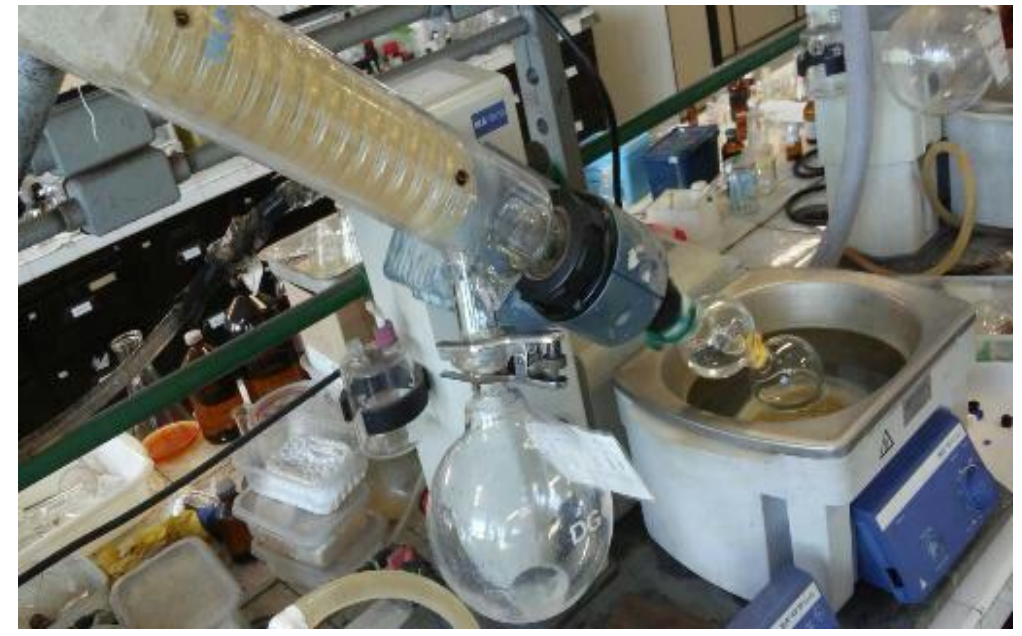

Fonte: autor 


\section{Resultados e Discussão}

Primeiro momento: relatos dos alunos sobre a atividade.

$\mathrm{Na}$ aula seguinte, os alunos comentaram sobre o funcionamento dos equipamentos e maquinários da fábrica, antes nunca visto por eles, sobre os produtos fabricados, o tempo de demora de uma análise química, a estrutura da empresa, o número de funcionários, da satisfação dos funcionários em trabalhar lá, dos benefícios oferecidos pela empresa aos seus funcionários, do ambiente de trabalho, que parecia ser ótimo, do ambiente externo da fábrica, que é bem arborizado e do enorme lago com seus patos e gansos.

A seguir, são mostrados trechos extraídos dos relatórios entregues pelos alunos, esses mostram as percepções dos alunos em relação à atividade proposta.

\section{Trecho 1: extraído do relatório entregue pelos alunos}

1 e 2 -"dentro da área de formação técnica, é essencial ter a experiência de uma visitação técnica a uma empresa para verificar como é o processo produtivo e como serão as atividades realizadas caso haja um estágio ou uma efetivação em alguma organização, e como pôr em prática aquilo que foi aprendido em sala. Sendo assim, eu apoio as visitas técnicas, pois essa visita técnica foi uma oportunidade de crescimento, foi possível agregar conhecimento não só na área química, 
como também em outras áreas técnicas, assim como em segurança do trabalho e gestão ambiental, por exemplo."

\section{Trecho 2: extraído do relatório entregue pelo aluno 3}

- “...essa visita técnica foi uma oportunidade de crescimento, pois foi possível agregar conhecimento não só na área química, como também em outras áreas técnicas..."

As impressões dos estudantes acerca da visitação à fábrica de cosméticos vai ao encontro do que é defendido por Artigas (2002) em relação à possibilidade de integração do conhecimento escolar à realidade observada no espaço profissional no qual são empregadas teorias e técnicas próprias da Química e de áreas afins. Além disso, a visitação em si seguiu um roteiro baseado no trabalho de Bamberger e Tal (2006) que possibilitou o estabelecimento do diálogo entre o guia da fábrica, o professor e os estudantes da turma durante todo o percurso. Esses relatos apontam para os resultados positivos da proposta da aula externa que complementou e acrescentou conhecimento, mostrou conteúdos que não são ministrados nas aulas teóricas da escola, possibilitou vivenciar a rotina de um profissional técnico em química, os equipamentos e maquinários existentes no ambiente industrial. 
Segundo momento: respostas ao questionário

A visita foi avaliada por meio de questionário com escala modelo Likert (Figura 2) e respondida pelos alunos que participaram da VTO. Eles poderiam responder ao questionário escolhendo uma única opção numérica variando de 1 a 5 . Somente 10 alunos responderam o questionário. Os dados foram coletados e as respostas adequadamente analisadas. A manipulação aritmética desses dados foi realizada através de cálculos das médias para cada assertiva, esse tipo de cálculo ajuda a nivelar o grau de concordância ou discordância em cada uma das assertivas e, segundo Rea e Parker (2000, p. 164) "essa manipulação tornou-se aceita porque se considera que o poder das informações obtidas supera de longe os custos associados ao relaxamento desses aspectos técnicos”.

Existem duas suposições em relação ao cálculo das médias das concordâncias das assertivas: os participantes possuem a mesma impressão em relação a cada categoria respondida ou os participantes discordam igualmente em relação a cada categoria respondida.

Os valores da média e do desvio padrão calculados para cada assertiva deste trabalho são mostrados na (Tabela 1), a seguir. 
Tabela 1. Médias e desvios padrão calculados para cada assertiva.

\begin{tabular}{|c|c|c|c|c|}
\hline \multicolumn{5}{|c|}{ ASPECTOS AFETIVOS } \\
\hline ASSERTIVAS & MEDIA & DESVPAD & $\begin{array}{c}\text { MEDIA } \\
\text { (MEDIA GLOBAL) }\end{array}$ & $\begin{array}{c}\text { DE SVPA D } \\
\text { (MEDIA GLOBin) }\end{array}$ \\
\hline Q1 & 4,8 & 0,42 & \multirow{5}{*}{4,6} & \multirow{5}{*}{0,6} \\
\hline Q2 & 4,9 & 0,32 & & \\
\hline Q5 & 4,3 & 0,95 & & \\
\hline Q6 & 4,6 & 0,70 & & \\
\hline Q11 & 4,4 & 0,84 & & \\
\hline \multicolumn{5}{|c|}{ ASPECTOS COGNITIVOS } \\
\hline ASSERTIVAS & MEDIA & DESVPAD & $\begin{array}{c}\text { MEDIA } \\
\text { (MEDIA GLOBAL) }\end{array}$ & $\begin{array}{c}\text { DESVPA D } \\
\text { (MEDIA GLOBAL) }\end{array}$ \\
\hline Q3 & 3,7 & 0,67 & \multirow{10}{*}{4,5} & \multirow{10}{*}{0,7} \\
\hline Q4 & 4,5 & 0,85 & & \\
\hline Q7 & 4,8 & 0,42 & & \\
\hline Q8 & 4,8 & 0,42 & & \\
\hline Q9 & 4,1 & 1,2 & & \\
\hline Q10 & 4,5 & 0,71 & & \\
\hline Q12 & 4,9 & 0,32 & & \\
\hline Q13 & 4,2 & 0,92 & & \\
\hline Q14 & 4,8 & 0,42 & & \\
\hline Q15 & 4,3 & 0,95 & & \\
\hline
\end{tabular}

Fonte: elaborado pelo autor.

As assertivas (Q9 - A visitação fez com que eu entendesse a importância de um técnico em química para uma indústria) e (Q15 - Durante a visitação verifiquei a presença do EPC nos ambientes da fábrica) apesar de apresentarem média superior a 4,0 mostraram um desvio padrão de (Q9 = 1,2 e Q15 = 0,95), essa heterogeneidade 
nos dados pode estar ligada diretamente ao fato dos alunos não terem interagido com um técnico em química. Eles interagiram com os analistas (graduados em química ou farmácia) durante a VTO e, apesar de terem estudado na escola os EPC, como são equipamentos de localização específica no ambiente industrial, a maioria dos alunos pode não ter visto os mesmos nos ambientes da fábrica.

As assertivas Q3 e Q9 do questionário mostram resultados que comprovam que só a realização da VTO não é suficiente para aprender coisas importantes de Química e, muito menos, entender a importância de um técnico em Química para uma indústria. Para que esses itens tenham uma resposta mais favorável, é necessário que o estudante vivencie o dia a dia desse ambiente, por isso, reforçamos ainda mais a obrigatoriedade do estágio supervisionado para os estudantes do ensino técnico.

Terceiro momento: produção dos cosméticos e extração dos óleos essenciais.

Mesmo o curso técnico possuindo ênfase em produção de cosméticos, a produção destes pelos alunos, no laboratório escolar, após a VTO, contribuiu ainda mais para a construção do conhecimento científico. Pois os estudantes têm poucas oportunidades de preparar cosméticos no decorrer do curso. 
O processo de preparo e extração dos óleos essenciais também foi novidade para a grande maioria dos alunos, pois devido à falta de alguns equipamentos e vidrarias na instituição de ensino, eles só tinham vistos os esquemas de destilação em recursos digitais.

É sabido que o conhecimento adquirido no decorrer do curso não se distancia da realidade da indústria, apenas encontra-se distante, algumas vezes, do dia a dia da formação do aluno.

\section{Conclusão}

A SD apresentada neste trabalho e que compõe o produto didático, "GUIA PRÁTICO PARA VISITAÇÃO TÉCNICA ORIENTADA: da visitação à indústria ao laboratório escolar" constitui-se num material de apoio para o professor. Mostra que é possível criar estratégias de ensino que motivem uma aprendizagem significativa, em que o conteúdo estudado na sala de aula ganha sentido e, no caso dos cursos técnicos, aproxima o aluno à sua futura área de atuação profissional.

Este relato de experiência tem por objetivo auxiliar o professor na execução de uma visitação técnica orientada a uma indústria Química cosmética, além de sugerir a aplicação de uma SD com propostas de atividades 
a serem cumpridas antes, durante e após a visitação. A proposta aqui apresentada não é única e inalterável, mas oferece e sugere um percurso que pode ser adaptado à visitação a outros espaços profissionais.

\section{Referências}

ARTIGAS, A. Turismo educativo em Curitiba. In: Cadernos de Pesquisa Turismo. Faculdades Integradas Curitiba, 2002.

BAMBERGER, Y.; TAL, T. Learning in a personal context: levels of choice in a free choice learning environment in science and natural history museum. Science Education, Hoboken, v. 91, n. 1, p. 75-95, 2006.

COSTA, R. L. da. Sequência didática aplicada ao ensino técnico em Química: da visitação à indústria ao laboratório escolar. 2019. 114 f. Dissertação (Mestrado Profissional em Ensino de Química)-Instituto de Química, Universidade Federal do Rio de Janeiro, Rio de Janeiro, 2019.

FREINET, C. A educação do trabalho. São Paulo: Martins Fontes, 1998.

GIORDAN, M.; GUIMARÃES,Y. A. F.; MASSI, L. Uma análise das abordagens investigativas de trabalhos sobre as sequências didáticas: tendências no ensino de ciências. In: ENCONTRO NACIONAL DE PESQUISAS EM EDUCAÇÃO EM CIÊNCIAS, 8, Anais... Campinas, 2011.

GIORDAN, M; GUIMARÃES, Y. A. F.; MASSI, L. Uma análise das abordagens investigativas de trabalhos sobre sequências didáticas: tendências no ensino de ciências. In: Atas do VIII 
ENCONTRO NACIONAL DE PESQUISA EM EDUCAÇÃO EM CIÊNCIAS. ABRAPEC, Campinas, 2011.

GOMES, F.; MACHADO, F. S.; COSTA, L. L. da; ALVES, B. H. P. Atividades Didático-Pedagógicas para o Ensino de Química Desenvolvidas pelo projeto PIBID-IFG. Química Nova na Escola, São Paulo-SP, Vol. 36, $\mathrm{N}^{\circ} 3$, p. 211-219, agosto de 2014.

GUENTHER, E. The essential oils. vols. 1, 2 e 3. Florida: Krieger Publishing Company, 1976.

JAPIASSU, H. O sonho transdisciplinar. Rio de Janeiro: Imago, 2006.

Lorenzi, H.; Matos, F.J.A. Plantas Medicinais no Brasil: nativas e exóticas. $2^{\mathrm{a}}$ ed. Nova Odessa, Instituto Plantarum, 2008.

OLIVEIRA, B. T.; SILVA, V. J. Teoria da Autodeterminação na compreensão da motivação da aprendizagem de Química dos alunos da Educação de Jovens e Adultos, R. Labore Ens. Ci., Campo Grande, v.1, n.1, p. 109 -127, 2016.

OLIVEIRA, G. et al.Visitas guiadas ao Museu Nacional: interações e impressões de estudantes da Educação Básica. Ciência \& Educação, Bauru, v.20 n.1, p. 227-242, 2014.

PAVIA, D. L., LAMPMAN, G. M., KRIZ, G. S.; ENGEL, R. G. Química orgânica experimental: técnicas de escala pequena. Bookman, 2009.

REA, L.; PARKER, R. Metodologia de Pesquisa: do planejamento à execução, São Paulo: Pioneira, 2000.

SAMPAIO, R. M. W. Freinet: evolução histórica e atualidades. 2 ed. São Paulo: Scipione, 2002. 
SANTOS, C. C. dos Investigando o Comportamento de Professores durante visitas escolares ao Museu Nacional. Rio de janeiro, 84f, 2017.

SANTOS, G. S. dos. A reforma da educação profissional e o ensino médio integrado: tendências e riscos. São Paulo, 2006.

SILVA, R. R. da; MACHADO, P. F. L.; TUNES, E. Experimentar sem medo de errar. In: SANTOS, W. L. P. dos; MALDANER, O. A. (Org.). Ensino de Química em Foco. Ijuí: Unijuí, 2010.

THIOLLENT, M. Metodologia da pesquisa-ação. São Paulo: Cortez: Autores Associados, 108p, 986.

VELOSO, M. P. Visita técnica: uma investigação acadêmica. Goiânia: Kelps, 2000.

ZABALA, A. A prática Educativa: como ensinar; tradução Ernani F. da F. Rosa. Porto Alegre: Artmed, 1998. 